\title{
Electroreduction of Benznidazole in Dimethylsulfoxide
}

\author{
M. L. P. M. Arguelho, ${ }^{a}$ G. M. Silva, ${ }^{b}$ and N. R. Stradiotto ${ }^{c, z}$ \\ ${ }^{a}$ Departamento de Quimica, USP, 14040-901, Ribeirão Preto, SP, Brazil \\ ${ }^{b}$ Departamento de Quimica, UFMS, 79100, Campo Grande, MS, Brazil \\ ${ }^{c}$ Instituto de Quimica, UNESP, 14801-970, Araraquara, SP, Brazil
}

The electrochemical behavior of benznidazole has been investigated in dimethylsulfoxide by cyclic voltammetry and controlledpotential electrolysis. The reduction occurs in two one-electron steps, where the first electron transfer corresponds to the reversible formation of the radical anion followed by a slow chemical reaction. The second electron transfer is attributed to the reduction of the radical anion to a dianion by an electrodic process involving a very fast cleavage of the dianion with the formation of a lactam derivative as the principal product of reduction in aprotic medium.

(C) 2001 The Electrochemical Society. [DOI: 10.1149/1.1342096] All rights reserved.

Manuscript submitted March 8, 2000; revised manuscript received October 16, 2000.

Nitroimidazoles are compounds with a wide range of biological effects, some of which have particular therapeutic value in human and animal treatment. These compounds have exhibited chemotherapeutic effects against protozoal and bacterial infection and tumorous regions. ${ }^{1}$

Benznidazole, $N$-benzil-(2-nitroimidazolyl) acetamide (1) is one of the most effective drugs for the treatment of Trypanosoma cruzi infection in the chronic phase as well as in the acute phase. ${ }^{2}$ Chagas's disease is common in countries of Latin America, where it is a social and economic question. ${ }^{3}$

However, little is known about benznidazole metabolism in the human body. Most of the studies on the pharmacological action of nitroimidazole suggest that the mechanism of cytotoxicity in protozoa is related to the enzymatic reduction of the nitro group and the affinity of the anion radicals to biomolecules. ${ }^{4}$<smiles>O=C(Cn1ccnc1[N+](=O)[O-])NCc1ccccc1</smiles>

1

The nitroimidazoles have been studied by electrochemical methods with success in diverse purposes such as the analytical determination in pharmaceutical formulations ${ }^{5,6}$ and the determination on the degree of interaction of these drugs with biomolecules, because it is known that many drugs exert part of their activity via an electron-transfer process.

The intention of this work is to investigate the electrochemical behavior of benznidazole in an aprotic medium using cyclic voltammetry and controlled-potential electrolysis in order to gain insight regarding the kinetic and the electrodic mechanism for benznidazole reduction in dimethylsulfoxide.

\section{Materials and Methods}

Benznidazole was kindly provided by Hoffmann-La Roche \& Co. The supporting electrolyte was tetrabutylammonium tetrafluorborate $\left(\mathrm{Bu}_{4} \mathrm{NBF}_{4}\right.$, Aldrich). The solvent was dimethylsulfoxide (DMSO, Merck).

Electrochemical measurements were carried out using a potentiostat (EG\&G PAR model 273), a function generator (EG\&G PAR model 175), and an X-Y recorder (EG\&G PAR model RE0089). The cell used for cyclic voltammetric experiments was of the threeelectrode type, with two compartments. The working electrode was

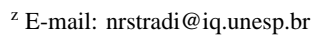

of vitreous carbon (Tokai Carbon Co, type GC30) with a disk area of $0.07 \mathrm{~cm}^{2}$, sealed in glass. The counter electrode was a Pt ring placed below the working electrode, and the reference was a saturated calomel electrode (SCE). The test solution was continuously blanketed with nitrogen for approximately $15 \mathrm{~min}$ before each measurement, and the working electrode surface was renewed by polishing with $0.05 \mu \mathrm{m}$ alumina followed by ultrasonification.

Controlled potential electrolyses were carried out in a threecompartment cell with a capacity of $10 \mathrm{~mL}$ using a vitreous carbon electrode with a geometric area of $4 \mathrm{~cm}^{2}$ as working electrode and a platinum gauze as auxiliary electrode and a SCE as reference electrode. The ultraviolet spectra (UV) were recorded on a Beckman Du-70 spectrometer, the quartz cell having an optical distance of 0.5 $\mathrm{cm}$. The electrolysis products were isolated by extraction with ether/ water phases, and residual water was eliminated by a rotation evaporator. ${ }^{1} \mathrm{H}$ and ${ }^{13} \mathrm{C}$ nuclear magnetic resonance (NMR) spectra were registered in DPX-300-Bruker 300 and $75 \mathrm{MHz}$ spectrometers, respectively.

\section{Results and Discussion}

Benznidazole exhibits two electron-transfer processes in the potential region 0.0 to $2.5 \mathrm{~V} v s$. SCE in aprotic medium (Fig. 1). The reduction was examined, and the cyclic voltammetric parameters are given in Table I.

When the direction of the negative scan is reversed between the first and the second cathodic peaks, an anodic wave is observed (peak 1a), which probably corresponds to the oxidation of the product formed during the first reduction. With increasing scan rate, the ratio of the anodic-to-cathodic peak heights increases, reaching unity, and the current function decreases slightly. Diffusional control of the cathodic current could be proved by the proportionality between the peak current and the square root of the scan rate and drug concentrations. This behavior of the cathodic current is followed by a shift of the peak potential to more negative values with increasing scan rate and drug concentration, and by a $60 \mathrm{mV}$ difference at low scan rates.

In accord with the literature, ${ }^{7}$ the first-step reduction of the nitroimidazoles derivatives in aprotic medium can happen for a reversible monoelectronic process with the formation of the respective anion radical. For benznidazole, the increase of the anodic current peak relative to the cathodic current peak and the shift of the reduction potential to more negative values with increasing scan rate indicate that the anion radical is being consumed by a very slow chemical reaction, in accord with an $E_{r} C_{i}$ mechanism. ${ }^{8}$

The second cathodic process shows complex behavior, with $\left|E_{\mathrm{p}}-E_{\mathrm{p} / 2}\right|$ greater than $200 \mathrm{mV}$. This second peak, seen at -1.87 $\mathrm{V}$ vs. $\operatorname{SCE}\left(v=0.01 \mathrm{~V} \mathrm{~s}^{-1}\right)$ shows a negative shift of potential equal to $160 \mathrm{mV}$ between scan rates of 0.01 and $1.0 \mathrm{~V} \mathrm{~s}^{-1}$. The current function becomes constant with increasing scan rate, and the process is not controlled by diffusion. Holding the potential for periods of 30 to $60 \mathrm{~s}$ after the first peak promotes an increase of the 


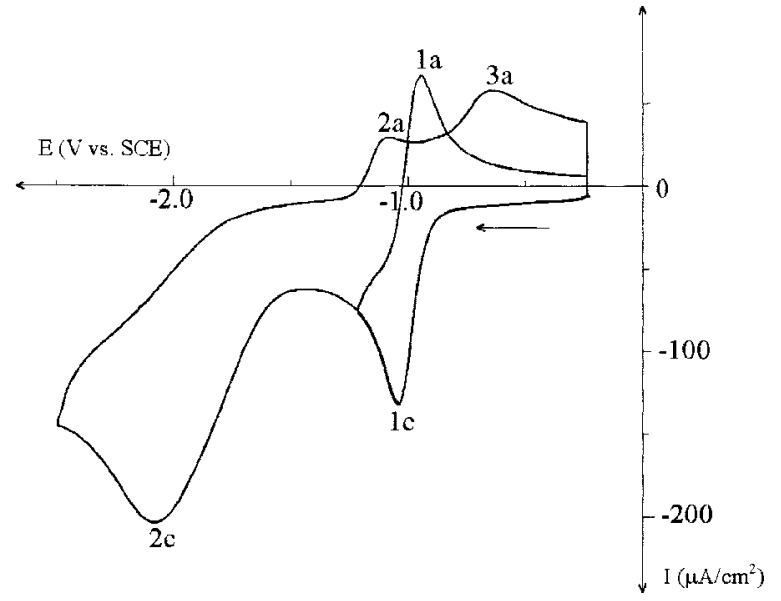

Figure 1. Cyclic voltammograms for $1.0 \mathrm{mmol} \mathrm{L}^{-1}$ benznidazole in $0.1 \mathrm{~mol}$ $\mathrm{L}^{-1} \mathrm{Bu}_{4} \mathrm{NBF}_{4} /$ DMSO. Scan rate $0.1 \mathrm{~V} \mathrm{~s}^{-1}$.

second cathodic current, and the ratio between the second and first peak heights increases proportionally to the scan rate. These results indicate that the second step is dependent on the first step.

The cathodic current is proportional to benznidazole concentration in the interval from 1 to $10 \mathrm{mmolL}^{-1}$, but the negative shift of the reduction potential with increasing concentration was equal to $45 \mathrm{mV}$, which is greater than that indicated in the literature for a system where only a simple reaction step is happening. Successives scans show that the reduction products of the second peak react with species in solution, decreasing the cathodic current of the first and second peaks in the second consecutive scans (Fig. 2).

The occurrence of an irreversible chemical reaction after electron transfer in the second peak could explain the disappearance or consumption of the electrogenerated product; this reductive process can be attributed to reduction of the anion radical formed in the first reduction step, giving rise to a strongly basic species such as a dianion derivative. The cleavage and dimerization are irreversible reactions often involved in electrodic processes with dianion derivatives.

Coulometric experiments indicate the involvement of one electron per molecule in the first peak. The second reduction step shows similar coulommetric results of one electron per molecule. Cyclic voltammograms obtained after electrolysis at $-1.2 \mathrm{~V} v s$. SCE indicate the formation of electroinactive products, as shown in Fig. 3; similar results were obtained with electrolysis after the second peak $(-2.4 \mathrm{~V} v s$. SCE).

Two reduction preparative electrolyses at controlled potential were carried out, and the organic compounds electrogenerated were isolated and identificated by conventional procedures. At the end of the electrolysis, the catholytes were removed and investigated by ultraviolet (UV) spectrommetry.

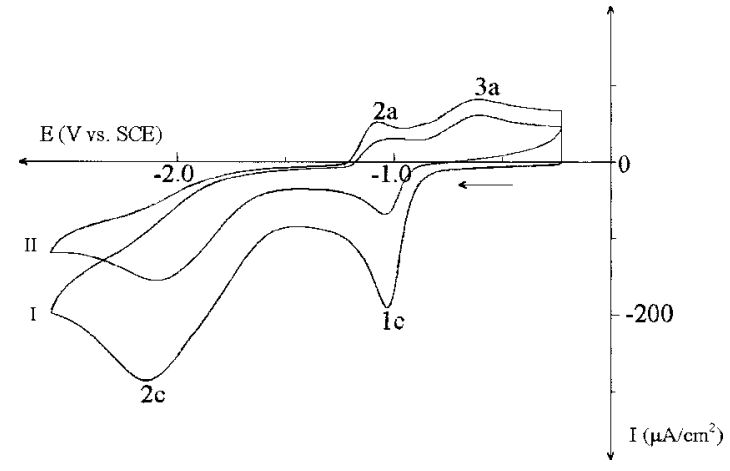

Figure 2. Cyclic voltammograms for $1.0 \mathrm{mmol} \mathrm{L}^{-1}$ benznidazole in $0.1 \mathrm{~mol}$ $\mathrm{L}^{-1} \mathrm{Bu}_{4} \mathrm{NBF}_{4} /$ DMSO. I, First scan; II, second scan.

The spectrum registered after electrolysis at $-2.4 \mathrm{~V} v s$. SCE (Fig. 4) shows the disappearance of the absorbance at $356 \mathrm{~nm}$ attributed to benznidazole, and at the same time two new peaks at 389 and $501 \mathrm{~nm}$ are formed.

The more significant isolated and identified species was a $\beta$-lactam derivative probably produced by cleavage of the dianion formed in the second reduction step. The structural characterization of the $\beta$-lactam derivative (2) was based on spectral data, notably ${ }^{1} \mathrm{H}$ and ${ }^{13} \mathrm{C}$ NMR spectra, in addition to the corresponding spectral data reported in the literature for benznidazole. ${ }^{9}$ Application of the shift parameters and the observed multiplicities of the signals for hydrogen for the electrolyzed product, together with data of ${ }^{13} \mathrm{C} \mathrm{NMR}$, are summarized in Table II

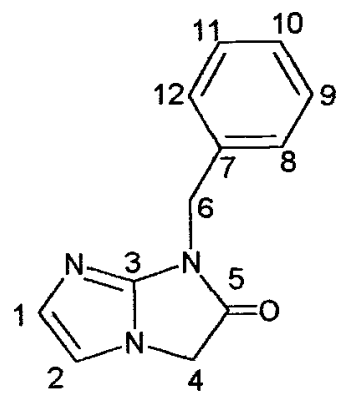

(2)

The formation of the $\beta$-lactam derivative as a consequence of the preferential cleavage reaction is not common to other studies. However, the occurrence of the formation of nitrite as a result of the cleavage after electrochemical reduction of metronidazole has been reported and associated with cytotoxicity effects of this nitroimidazole. ${ }^{10}$

Table I. Cyclic voltammetric parameters of $1.0 \mathrm{mmolL}^{-1}$ benznidazole in $\mathrm{DMSO} / \mathrm{Bu}_{4} \mathrm{NBF}_{4}\left(0.1 \mathrm{molL}^{-1}\right)$ at a vitreous carbon electrode.

1 st reduction process

\begin{tabular}{cccc}
\cline { 2 - 3 } $\begin{array}{c}\text { Potential } \\
\text { scan rate } \\
(v)\left(\mathrm{V} \mathrm{s}^{-1}\right)\end{array}$ & $\begin{array}{c}E_{\mathrm{pc} 1} \\
(\mathrm{~V})\end{array}$ & $-i_{\mathrm{pa}} / i_{\mathrm{pc} 1}$ & $\begin{array}{c}-i_{\mathrm{pc} 1} v^{-1 / 2} c^{-1} \\
1 \cdot 10^{-4} \mathrm{~A} \\
\left(\mathrm{~V}^{-1 / 2} \mathrm{~s}^{1 / 2} \mathrm{~mol} \mathrm{~L}\right)\end{array}$ \\
\hline 0.01 & 1.01 & 0.90 & 8.19 \\
0.03 & 1.01 & 0.90 & 8.18 \\
0.05 & 1.03 & 0.92 & 8.10 \\
0.10 & 1.05 & 0.93 & 8.11 \\
0.30 & 1.07 & 0.97 & 8.03 \\
0.50 & 1.10 & 0.99 & 7.71
\end{tabular}

2nd reduction process

\begin{tabular}{ccc}
\hline & & $-i_{\mathrm{pc} 1} v^{-1 / 2} c^{-1}$ \\
$(\mathrm{~V})$ & & $1 \cdot 10^{-4} \mathrm{~A}$ \\
1.87 & $-i_{\mathrm{pc} 2} / i_{\mathrm{pc} 1}$ & $\left(\mathrm{~V}^{-1 / 2} \mathrm{~s}^{1 / 2} \mathrm{~mol} \mathrm{~L}\right.$ \\
1.90 & 0.89 & 8.41 \\
1.94 & 1.04 & 8.52 \\
2.00 & 1.10 & 8.79 \\
2.06 & 1.14 & 9.22 \\
2.10 & 1.24 & 9.23 \\
& 1.30 & 9.30
\end{tabular}




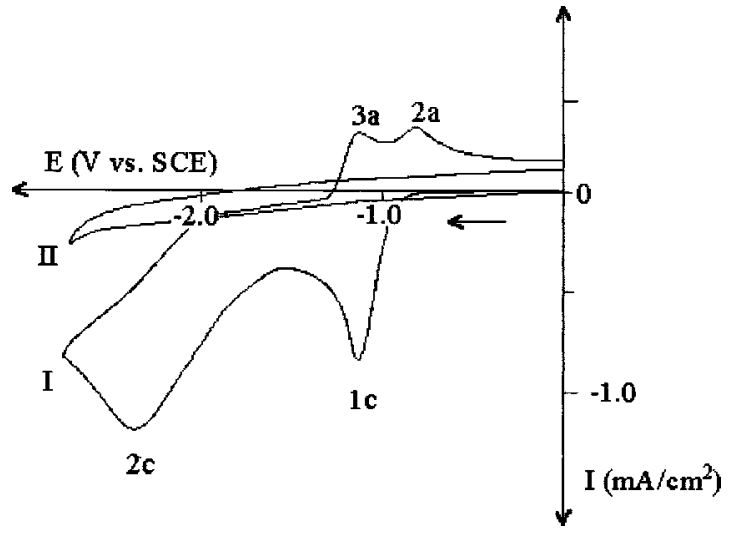

Figure 3. Cyclic voltammograms of $10 \mathrm{mmol} \mathrm{L}^{-1}$ benznidazole in $0.1 \mathrm{~mol}$ $\mathrm{L}^{-1}$ of $\mathrm{Bu}_{4} \mathrm{NBF}_{4} / \mathrm{DMSO}$. I, Before; II, after electrolysis at $-1.2 \mathrm{~V} v$. SCE. $v=0.1 \mathrm{~V} \mathrm{~s}^{-1}$

Table II. ${ }^{1} \mathrm{H}(300 \mathrm{MHz})$ and ${ }^{13} \mathrm{C}(75 \mathrm{MHz})$ spectral data ${ }^{\mathrm{a}}$ for compound 2 in $\mathrm{CDCl}_{3}$.

\begin{tabular}{|c|c|c|}
\hline Atom number & ${ }^{1} \mathrm{H} \delta(\mathrm{m}, \mathrm{J})$ & ${ }^{13} \mathrm{C} \delta$ \\
\hline 1 & $6.87(\mathrm{~d}, \mathrm{~J}=1.56)$ & 128.22 \\
\hline 2 & $6.80(\mathrm{~d}, \mathrm{~J}=1.56)$ & 113.24 \\
\hline 3 & - & 149.89 \\
\hline 4 & $4.90(\mathrm{~s})$ & 49.21 \\
\hline 5 & - & 170.93 \\
\hline 6 & $4.41(\mathrm{~s})$ & 44.31 \\
\hline 7 to 12 (aromatic) & 7.28 to $7.53(\mathrm{~m})$ & $\begin{array}{l}135.31(\mathrm{C} 7) \\
128.78(\mathrm{C} 8 \text { to } \mathrm{C} 12)\end{array}$ \\
\hline
\end{tabular}

${ }^{\text {a }}$ Chemical shift in $\delta(\mathrm{ppm})$ and coupling constant $(\mathrm{J})$ in $\mathrm{Hz}$.

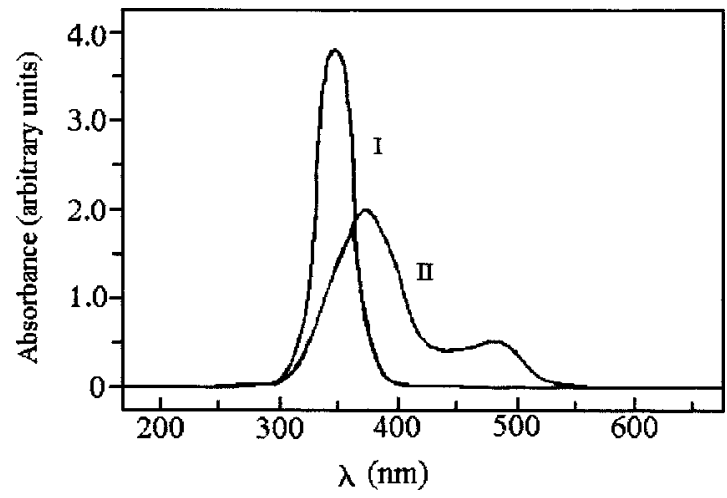

Figure 4. Spectra of the electrolyzed solutions of $10.0 \mathrm{mmol} \mathrm{L}^{-1}$ benznidazole in $0.1 \mathrm{M} \mathrm{Bu}_{4} \mathrm{NBF}_{4} / \mathrm{DMSO}$. I, Before electrolysis; II, after $60 \mathrm{~min}$ of electrolysis at $-2.4 \mathrm{~V} v s$. SCE.

In most of these electrochemical studies, the reduction of an anion radical to a dianion at more negative potentials depends on the stability of the anion radical in solution, since the reduction of the nitroso derivative forms starting from the dianion, and chemical transformation to azoxy and azo derivatives occurs through an electrodic process involving three electrons. ${ }^{11}$ Few electrodic processes for the reduction of the nitroimidazoles in aprotic medium have been reported in the literature, especially for the second reductive process.

The mechanism proposed for benznidazole reduction in DMSO can be summarized by Scheme I.
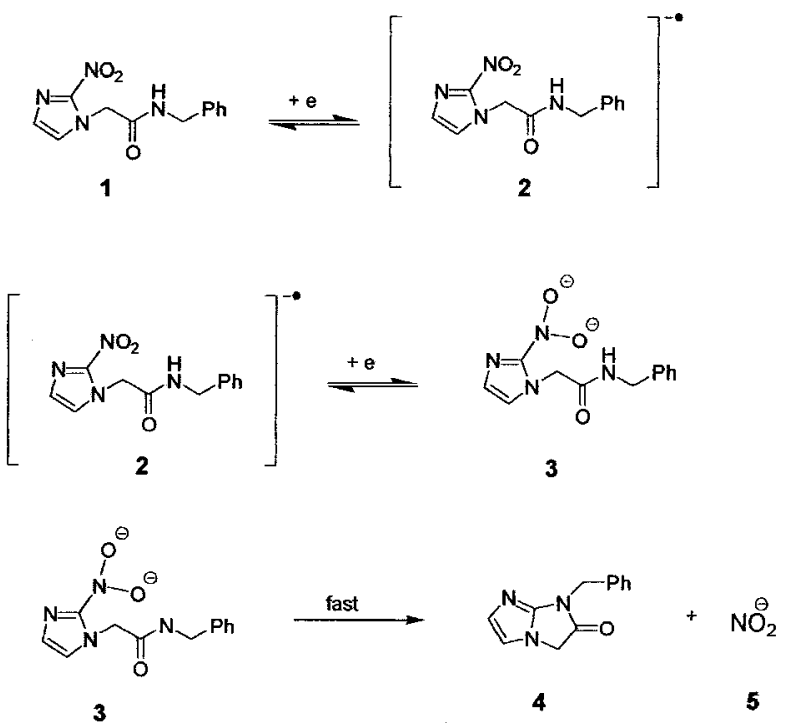

Scheme I. Mechanism for the electrochemical reduction of the benznidazole in aprotic medium.

\section{Acknowledgments}

The authors are grateful to CAPES and FAPESP for financial support.

Universidade Estadual Paulista (UNESP) assisted in meeting the publication costs of this article.

\section{References}

1. D. I. Edwards, J. Antimicrob. Chemother, 31, 9 (1993).

2. R. Viotti, C. Vigliano, H. Armenti, and E. Segura, Am. Health J., 127, 151 (1994).

3. World Bank, World Development Report 1993: Investing in Health, Oxford University Press, Oxford (1993).

4. J. H. Tocher and D. I. Edwards, Biochem. Pharmacol., 48, 1089 (1994).

5. Z. Wang, H. Zhou, and S. Zhou, Talanta, 40, 1075 (1993).

6. J. S. Barbeira, G. M. Silva, M. L. P. M. Beatriz, and N. R. Stradiotto, J. Pharm. Biomed. Sci., 20, 723 (1999).

7. D. Barety, B. Resibois, G. Vergoten, and Y. Moschetto, J. Electroanal. Chem., 162, 335 (1984)

8. Southampton Electrochemistry Group, Instrumental Methods in Electrochemistry, p. 179, John Wiley \& Sons, Inc., New York (1985).

9. M. S. Nothenberg and A. Korolkovas, Rev. Farm Bioquím., 19, 1 University Sao Paulo (1983).

10. H. Lund, in Organic Electrochemistry, M. M. Baizer and H. Lund, Editors, p. 295, Marcel Dekker Inc., New York (1983).

11. E. Gattavecchia, D. Tonelli, A. Breccia, and S. Roffia, Int. J. Radiat. Biol., 42, 105 (1982). 